Article

\title{
Laser Cladding of Embedded Sensors for Thermal Barrier Coating Applications
}

\author{
Yanli Zhang ${ }^{1,2}$, Daniel Emil Mack ${ }^{1, *} \mathbb{C D}^{\mathbb{C}}$, Georg Mauer ${ }^{1}$ (D) and Robert Vaßen $^{1}$ (1) \\ 1 Materials Synthesis and Processing (IEK-1), Institute of Energy and Climate Research, \\ Forschungszentrum Jülich $\mathrm{GmbH}, 52425$ Jülich, Germany; yanli_zhang@aliyun.com (Y.Z.); \\ g.mauer@fz-juelich.de (G.M.); r.vassen@fz-juelich.de (R.V.) \\ 2 China Center for Information Industry Development (CCID), Beijing 100048, China \\ * Correspondence: d.e.mack@fz-juelich.de; Tel.: +49-2461-61-2971
}

Received: 12 March 2018; Accepted: 25 April 2018; Published: 4 May 2018 updates

\begin{abstract}
The accurate real-time monitoring of surface or internal temperatures of thermal barrier coatings (TBCs) in hostile environments presents significant benefits to the efficient and safe operation of gas turbines. A new method for fabricating high-temperature K-type thermocouple sensors on gas turbine engines using coaxial laser cladding technology has been developed. The deposition of the thermocouple sensors was optimized to provide minimal intrusive features to the TBC, which is beneficial for the operational reliability of the protective coatings. Notably, this avoids a melt pool on the TBC surface. Sensors were deposited onto standard yttria-stabilized zirconia (7-8 wt \% YSZ) coated substrates; subsequently, they were embedded with second YSZ layers by the Atmospheric Plasma Spray (APS) process. Morphology of cladded thermocouples before and after embedding was optimized in terms of topography and internal homogeneity, respectively. The dimensions of the cladded thermocouple were in the order of 200 microns in thickness and width. The thermal and electrical response of the cladded thermocouple was tested before and after embedding in temperatures ranging from ambient to approximately $450{ }^{\circ} \mathrm{C}$ in a furnace. Seebeck coefficients of bared and embedded thermocouples were also calculated correspondingly, and the results were compared to that of a commercial standard K-type thermocouple, which demonstrates that laser cladding is a prospective technology for manufacturing microsensors on the surface of or even embedded into functional coatings.
\end{abstract}

Keywords: laser cladding; thermocouple sensor; laser cladded sensors; Seebeck coefficient; minimal heat affected zone (HAZ); thermal barrier coatings (TBCs)

\section{Introduction}

An increase in the combustion temperatures in gas turbine engines can satisfy demands for higher efficiency. As a result, thermal barrier coatings (TBCs) are widely used in gas turbine engines as well as in diesel engines for power generation to protect the superalloy substrate from high temperatures, corrosion, and oxidation [1-3]. However, exploiting the full range of allowable engine operating temperatures while avoiding any risk of overheating its components requires accurate knowledge of the turbine blade temperature. Therefore, effective monitoring and diagnosis in such harsh operating conditions is of critical importance. If critical operating conditions could be continuously monitored in real-time, problems could be detected and solved during the processing cycle. So-called "smart" coatings generally are intended to add functionalities beyond their main purpose or to be able to adopt to certain stimuli [4]. In the context of gas turbines, "smart" coatings were proposed for in situ monitoring during the operation of turbine blades to better control the surrounding environment as well as enable the design of coatings with appropriate structures [5]. 
To date, several technologies have been proposed for the manufacture of smart coatings. Fasching et al. [5] produced thermocouples using a mask-based wire arc deposition process that yielded Seebeck coefficients reasonably close to those of commercial devices; these thermocouples were tested up to $200{ }^{\circ} \mathrm{C}$, the feature sizes of which were in the order of $200 \mu \mathrm{m}$. The fabrication of thin-film thermocouple sensors or strain gauge sensors was demonstrated by applying stenciled shadow masks or a photolithography technique combined with chemical etching during a sputter-deposition process in a class 1000 clean room [6,7]. Both Theophilou et al. [8] and Longtin et al. [9] suggested the manufacture of sensors using a traditional thermal spray process which employed masks to pattern the device or by subsequent laser micromachining. Recently, thermal spray techniques, in conjunction with a novel multistage aperture-collimator system, made it possible to deposit sensors with tracks at dimensions of $200 \mu \mathrm{m}$ directly onto the surface and to be embedded into TBCs, which could survive in harsh environments $[10,11]$. However, all of the above-mentioned technologies have noticeable disadvantages; all are time-consuming because of either the application of masks or the vacuum-deposition conditions or have an extreme low efficiency of deposition.

In the current study, laser cladding is introduced as an alternative process for the manufacture of smart coatings in gas turbine application; however, this process requires several changes to typical conditions. In general, laser cladding is a well-established industrial technology, which utilizes a focused or defocused laser beam as a heat source to join two similar or different materials [12]. A small volume at the surface level of the substrate is molten and materials are added to the melt in the form of powders or wires to create a new layer of fused material. Laser cladding is used for a large variety of applications and materials, comprising polymers as well as alloys and ceramics for use at high temperature. Current trends of laser cladding with respect to turbine application include the manufacture of multifunctional protective coatings for the modification of surface properties, such as wear and corrosion resistance, abrasion and thermal resistance, or the repair of critical components with a laser beam [13-16]. Given high-speed cladding and the characteristics of rapid solidification processes, structures homogeneous in terms of low porosity and the absence of cracks may be obtained on the surface of work pieces $[17,18]$.

Unlike the traditional cladding process, the deposition of metal tracks to form a sensor, e.g., a thermocouple on turbine components coated with atmospheric plasma-sprayed (APS) TBC, needs to be as minimally intrusive to the substrate as possible. The heterogeneous microstructure of the porous ceramic typically is optimized for low-thermal conductivity and high-strain tolerance to achieve improved thermal protection capabilities and thermal shock resistance. Any densification or cracking induced on melting and resolidification during the cladding process would result in a reduced spallation lifetime of the coating under thermomechanical loads imposed in operation [19]. Therefore, the aim of the current study is to adapt process conditions in laser cladding in a way that, during deposition of a small-scale metallic track, the microstructure of the porous YSZ (yttria-stabilized zirconia) substrate does not deteriorate or partly melt; it also aims to demonstrate sensor functions of such structures after they are embedded into the ceramic TBC. Several advantages are coupled with this route of manufacture, as it requires neither vacuum processing nor the applications of masks.

Process parameters such as laser power, focus diameter, scan velocity, and powder feeding rate were varied during micro cladding to reduce the heat load towards the ceramic substrate while ensuring the melting of feedstock for the formation of continuous clads. In a preliminary set of experiments, the feasibility of using a defocused laser beam and limited power densities was evaluated. In a second step, optimized clads were achieved through the use of increased powder feeding rates. Feature sizes of clads and the microstructure of the substrate were characterized by confocal laser scanning microscopy and metallographic analysis. K-type thermocouple sensors, fabricated with optimized setup on a thermally sprayed YSZ layer, were embedded into the TBC structure by subsequent deposition of an additional ceramic layer. The resistance of the cladded thermocouple was measured and compared to that of the commercial standard K-type thermocouples. The thermal and electrical performance of the manufactured thermocouple sensor was also evaluated and characterized at high temperatures. 


\section{Experimental}

Metal sheets from Inconel 738 or aluminum with a $200 \mu \mathrm{m}$ thick layer of atmospheric plasma sprayed 7-8 wt \% YSZ (yttria stabilized zirconia) were used as substrates for laser cladding, the dimensions of which were approximately $50 \times 50 \times 3 \mathrm{~mm}^{3}$. The porosity of the TBC coatings was approximately $18 \%$, as determined by the mercury intrusion method. Substrates were cleaned in ethanol and dried with compressed air before deposition of sensor structures.

Gas-atomized powders of alumel and chromel, suitable to form a K-type thermocouple, were used as feedstock for laser cladding in this study (Sandvik Osprey, Neath, UK). The chemical compositions are listed in Table 1. The particle diameter for the alumel powder was in the range of 2.6-20 $\mu \mathrm{m}$ with a median particle size of $7.4 \mu \mathrm{m}$. The particle diameter of the chromel powder ranged from 3.5 to $35 \mu \mathrm{m}$, with a median particle size of $12.1 \mu \mathrm{m}$. Before cladding, both powders were dried in an oven at $150{ }^{\circ} \mathrm{C}$ for $24 \mathrm{~h}$ to prevent clogging of the powders.

Table 1. Elemental composition of powders (by weight, wt \%).

\begin{tabular}{cccccc}
\hline Powder & Ni & Al & Mn & Si & Cr \\
\hline alumel & Balance & 1.9 & 2.3 & 1.3 & - \\
chromel & Balance & - & - & - & 9.8 \\
\hline
\end{tabular}

The cladding experiments were carried out using a multi-axis computerized numerical-controlled (CNC) system, TruLaser Cell 3008 (Trumpf, Ditzingen, Germany), equipped with a Nd:YAG fiber laser TruFiber 400 ( $400 \mathrm{~W}, \lambda=1.064 \mu \mathrm{m})$. A modified powder feeder (Oerlikon Metco, Wohlen, Switzerland) was utilized for powder supply, with argon as the carrier gas. The cladding powders, delivered at a given mass flow rate, were injected into the laser spot onto the ceramic substrate through a coaxial jet-nozzle Coax 8 (ILT, Aachen, Germany), as shown in Figure 1. Additionally, the inner zone of the nozzle had been purged by argon as a shielding gas. The working distance of the powder nozzle was fixed at $7 \mathrm{~mm}$ to the substrate surface to utilize the minimum spot size of the powder feed of about $200 \mu \mathrm{m}$.

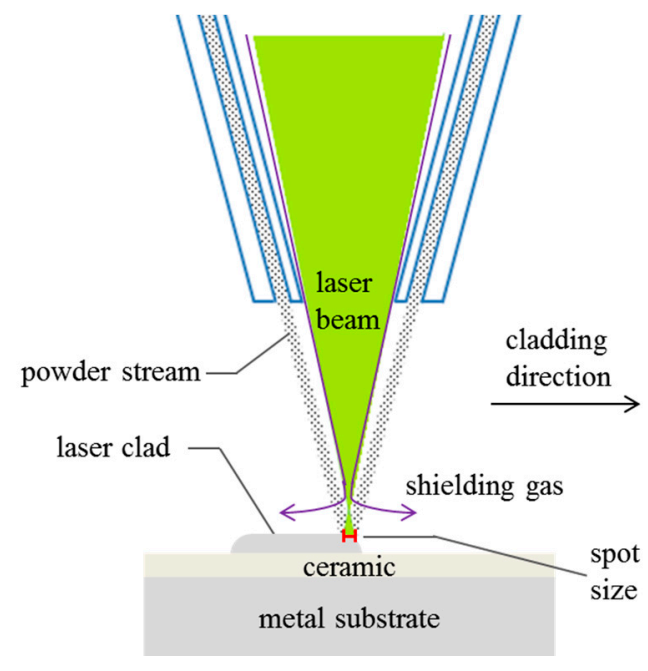

Figure 1. Schematic of laser cladding process.

Two sets of experiments were performed for the identification of suitable process parameters in laser deposition. In a first set of experiments, laser cladding of alumel feedstock was carried out by varying the laser power $\left(P_{\mathrm{L}}\right)$ from 50 to $110 \mathrm{~W}$ while keeping the spot size (diameter $d_{\mathrm{S}}$ ), the scanning speed $\left(v_{\mathrm{S}}\right)$, the powder feeding rate $\left(f_{\mathrm{F}}\right)$, the carrier gas rate $\left(f_{\mathrm{C}}\right)$, and the protective gas rate $\left(f_{\mathrm{P}}\right)$ constant, which were $d_{\mathrm{S}}=984 \mu \mathrm{m}, v_{\mathrm{S}}=400 \mathrm{~mm} / \mathrm{min}, f_{\mathrm{F}}=1.7 \mathrm{~g} / \mathrm{min}, f_{\mathrm{C}}=10 \mathrm{~L} / \mathrm{min}$, and $f_{\mathrm{P}}=10 \mathrm{~L} / \mathrm{min}$, 
respectively. In a second set of experiments, laser cladding of both alumel and chromel feedstock was carried out by varying the powder feeding rate $\left(f_{\mathrm{F}}\right)$ in the range of $6.6-13.2 \mathrm{~g} / \mathrm{min}$ while keeping the spot size, the scanning speed, the laser power, the carrier gas rate, and the protective gas rate constant, which were $d_{\mathrm{S}}=156 \mu \mathrm{m}, v_{\mathrm{S}}=1000 \mathrm{~mm} / \mathrm{min}, P_{\mathrm{L}}=15 \mathrm{~W}, f_{\mathrm{C}}=10 \mathrm{~L} / \mathrm{min}$, and $f_{\mathrm{P}}=10 \mathrm{~L} / \mathrm{min}$, respectively.

The macroscopic morphology of the clads was examined under a stereo microscope (Olympus, Tokyo, Japan). The microstructure of tracks was characterized under a confocal laser microscope (Keyence, Osaka, Japan), after metallographic cross sectioning. The dimensions of cladded tracks were determined by means of a Cyberscan topographer (CyberTECHNOLOGIES GmbH, Dietersheim, Germany) and estimated from cross sections. The resistivity for cladded tracks was estimated by a self-assembled, direct-current, four probe tester prior to any occasional sectioning.

K-type thermocouples were fabricated in the shape of a cross under optimized parameters onto a $30 \times 40 \times 3.5 \mathrm{~mm}^{3}$ aluminum substrate that had been previously coated with $200 \mu \mathrm{m}$ of APS-sprayed TBC (8YSZ). Subsequently, the crossed thermolegs were covered by a second thermally sprayed YSZ layer. Easily accessible electrical junctions were conserved by masking the bared tips with a metallic steel sheet while spraying. For the evaluation of the thermo-electric coefficient of the cladded thermocouple before and after embedding with a second ceramic layer, the thermal and electrical response was measured at elevated temperatures. Figure 2 shows a photo of the specimen, with a sketch of the external set-up for the measurement. To realize the electrical contact, the negative leg of alumel and positive leg of chromel were mechanically attached to NiAl and $\mathrm{NiCr}$ compensation wires, respectively. Fixation was induced by metallic clips for pressure and a piece of glass for insulation. The entire setup was placed inside a furnace while the other sides of the compensation wires were externally connected to a data acquisition device accompanied by a transducer. A commercial K-type thermocouple was also mounted on top of the cladded thermocouple junction area for comparison to monitor the true sample temperature during the oven test; it was also connected to the data collection device. The sample was placed inside the furnace with $5 \mathrm{~K} / \mathrm{min}$ heating rate under an argon protective gas atmosphere. The voltage and temperatures across the junction were recorded over a temperature range from ambient to $450{ }^{\circ} \mathrm{C}$. Temperature was limited to prevent damage to the aluminium substrate or the materials used for contacting the thermocouple. In future application scenarios, the electrical contact could presumably be achieved at cold positions of the components, e.g., the fir-tree section of a turbine blade.

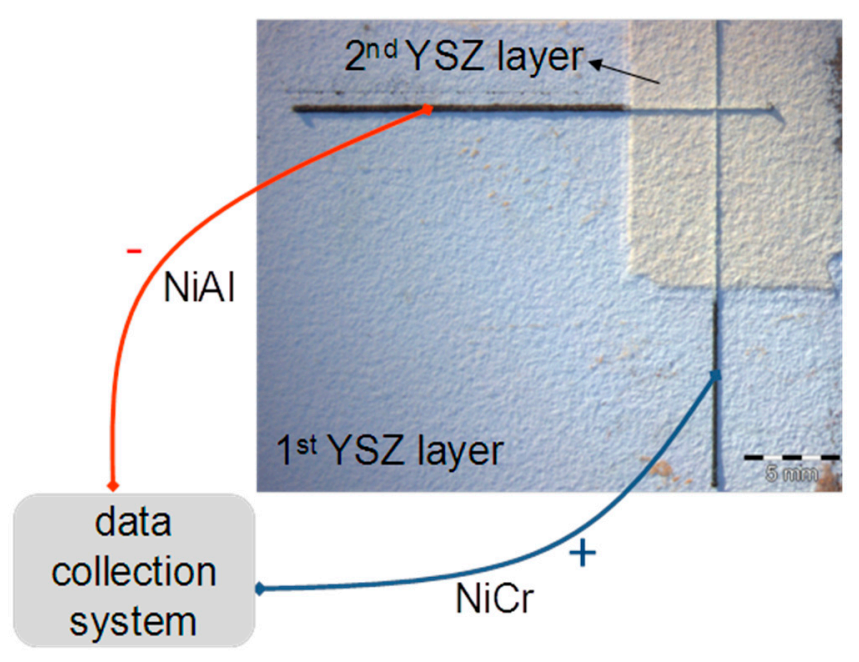

Figure 2. A photo of an embedded thermocouple and a set-up for collecting temperature signals. Parameters of laser cladding have been chosen according to optimized microstructures as discussed in Section 3.2. 


\section{Results and Discussion}

\subsection{Deterioration of Porous YSZ Substrate on Cladding with Defocused Laser Beam and Limited Power Densities}

In the first set of experiments conducted with the alumel feedstock, a defocused laser beam was applied to increase the time of flight of the particles within the laser beam and thereby to increase the energy absorbed by the metal particles. At the same time, the spreading of the melt formed on the surface to reduce the height of tracks was fostered as a larger area was heated.

Based on Equation (1):

$$
P \times t=F \times t \times\left[c_{\mathrm{p}} \times\left(T_{\mathrm{m}}-T_{\mathrm{RT}}\right)+H_{\text {fusion }}\right]
$$

where $P$ is the necessary power, $t$ is the cladding time, $F$ is the powder feeding rate, $c_{\mathrm{p}}$ is the specific heat capacity, $T_{\mathrm{m}}$ is the melting temperature, $T_{\mathrm{RT}}$ is the room temperature, and $H_{\text {fusion }}$ is the latent heat of fusion, i.e., the energy necessary to achieve complete melting can be estimated to about $1 \mathrm{~kJ} / \mathrm{g}$ $\left(c_{\mathrm{p}}=0.53 \mathrm{~J} / \mathrm{g} \cdot \mathrm{K}, H_{\text {fusion }}=300 \mathrm{~J} / \mathrm{g}, T_{\mathrm{m}}=1399{ }^{\circ} \mathrm{C}\right)$. Considering some fraction of laser light reflected and scattered by the metal particles, the lowest power of the laser was chosen at $50 \mathrm{~W}$ to achieve full melting of the supplied feedstock, which had been fed at the minimum stable rate $(1.7 \mathrm{~g} / \mathrm{min})$. At the same time, melting of the substrate was not expected owing to the much higher energy necessary to melt YSZ (roughly $2 \mathrm{~kJ} / \mathrm{g}$ ) and the much smaller coefficient of absorption at the laser wavelength, which was found in the order of only $0.1 \mathrm{~cm}^{-1}$ for plasma-sprayed TBCs [20].

The morphology of the tracks manufactured with the defocused laser is shown in Figures 3 and 4. From the top view in Figure 3, it can be seen that beads significantly larger than the original particles were observed, with powers at 50-100 W. This indicates that a larger fraction of feedstock particles were heated well above the melting temperature, which allowed them to fuse together. The size of the bead heads had a tendency to become smaller when the laser power increased; additionally, the clad surface became quite smooth and continuous when the power was increased to $110 \mathrm{~W}$. This may be correlated to a further increase of the steadily molten volume, which allowed for spreading and coalescence of the beads. The latter hypothesis is also supported by the behavior of the apparent track width as a function of the laser power, as illustrated in Figure 5. The track width displayed a strong dependence on the laser power and increased from 1.0 to $1.7 \mathrm{~mm}$ because of increased energy input per unit length when the laser power was increased. Notably, the track width at increased laser power exceeded the width of the laser spot, which also supports the conclusion of the spreading of melt.

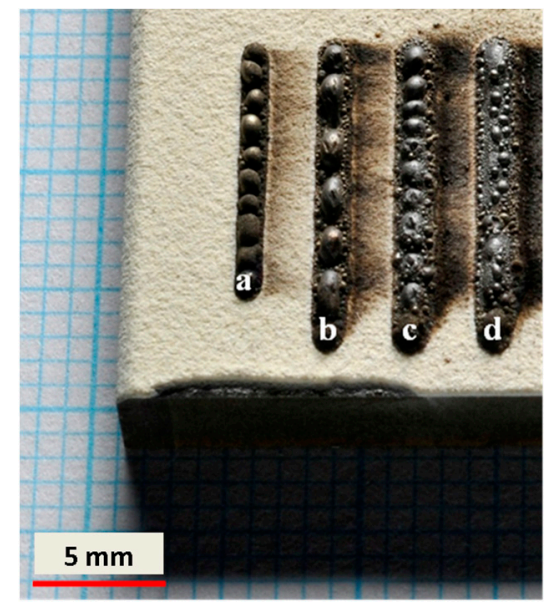

Figure 3. Surface morphologies of clads from alumel feedstock at different parameters from the top view. $v_{\mathrm{S}}=400 \mathrm{~mm} / \mathrm{min}, d_{\mathrm{S}}=0.984 \mathrm{~mm}, f_{\mathrm{F}}=1.7 \mathrm{~g} / \mathrm{min}, f_{\mathrm{C}}=f_{\mathrm{P}}=10 \mathrm{~L} / \mathrm{min}$. (a) $P_{\mathrm{L}}=50 \mathrm{~W} ;(\mathbf{b}) P_{\mathrm{L}}=80 \mathrm{~W}$; (c) $P_{\mathrm{L}}=100 \mathrm{~W} ;(\mathbf{d}) P_{\mathrm{L}}=110 \mathrm{~W}$. 

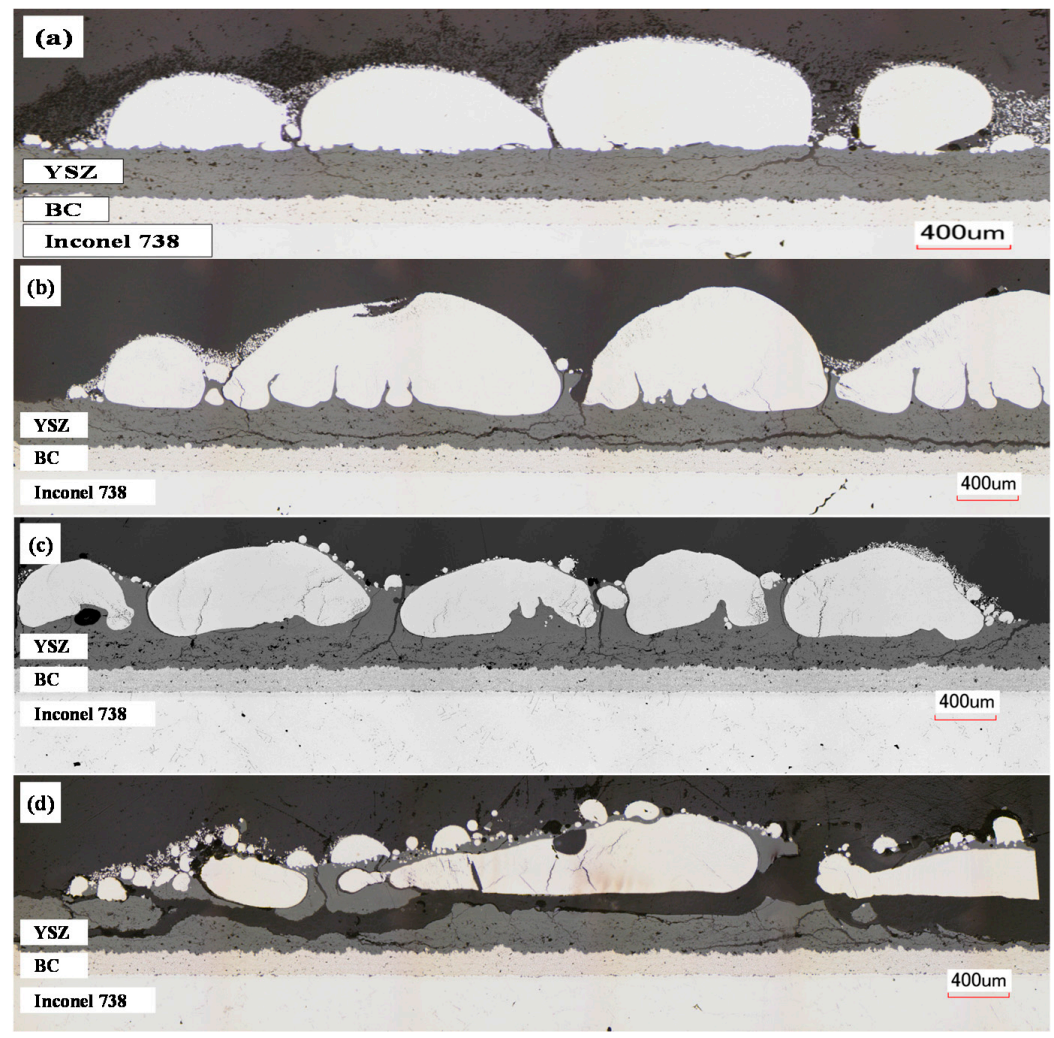

Figure 4. Cross sections of tracks produced with different process parameters from alumel feedstock under a laser microscope. $v_{\mathrm{S}}=400 \mathrm{~mm} / \mathrm{min}, d_{\mathrm{S}}=0.984 \mathrm{~mm}, f_{\mathrm{F}}=1.7 \mathrm{~g} / \mathrm{min}, f_{\mathrm{C}}=f_{\mathrm{P}}=10 \mathrm{~L} / \mathrm{min}$. (a) $P_{\mathrm{L}}=50 \mathrm{~W}$; (b) $P_{\mathrm{L}}=80 \mathrm{~W}$; (c) $P_{\mathrm{L}}=100 \mathrm{~W} ;$ (d) $P_{\mathrm{L}}=110 \mathrm{~W}$.

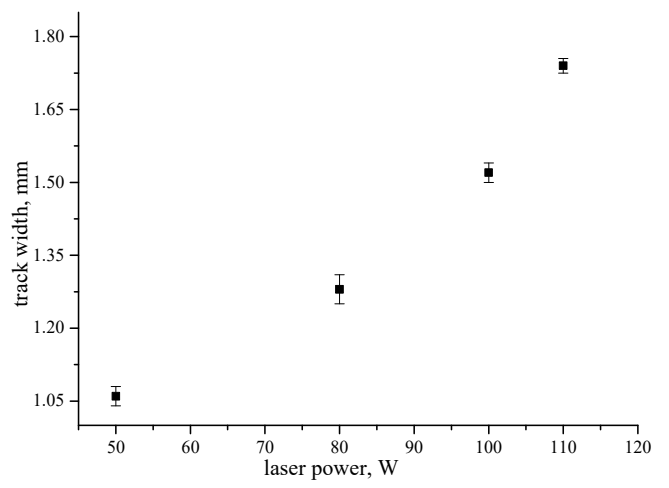

Figure 5. Width of cladded tracks from alumel feedstock as a function of the laser power. Common parameters: $v_{\mathrm{S}}=400 \mathrm{~mm} / \mathrm{min}, d_{\mathrm{S}}=0.984 \mathrm{~mm}, f_{\mathrm{F}}=1.7 \mathrm{~g} / \mathrm{min}, f_{\mathrm{C}}=f_{\mathrm{P}}=10 \mathrm{~L} / \mathrm{min}$.

The resistivity of cladded alumel tracks was roughly estimated from the outer dimensions of clads and their measured resistance. Results showed that only the thermoleg produced with $50 \mathrm{~W}$ was conductive, despite a wavy surface morphology. The resistivity of this track in Figure 3a was approximately $1.8 \mu \Omega \cdot \mathrm{m}$. This much larger than the reported value $0.294 \mu \Omega \cdot \mathrm{m}$ [21], which indicates that the track was either inhomogeneous in terms of cross-sectional areas or defects and impurities at the grain boundaries of the bulk material may have reduced conductivity.

To identify the mechanisms which lead to either a conductive or non-conductive state, cross sections of the above deposited tracks along the cladding directions were prepared and investigated by a laser microscope. Corresponding micrographs are given in Figure 4, which clearly indicate gaps between the beads, causing the inhibition of electrical currents. Additionally, the increase of the laser power not only 
increased the width of the tracks but also elongated the beads in the direction of cladding and the length of intercepting gaps. Reasons for the conductivity of the first track may be the slight contact of the big beads and small-sized, non-coalesced particles. The beads in Figure $4 b, c$ were discontinuous, causing these two tracks to be non-conductive. The track in Figure 4c even began to be buried by the YSZ coating. The last track in Figure $4 \mathrm{~d}$ was totally buried and discontinuous, which made this track non-conductive.

Figure 4 also clearly demonstrates that, with an increase of laser power, the influence to the substrate increased correspondingly. The tracks began to penetrate the insulating YSZ coatings and were even buried within them. The higher the laser power was, the deeper the tracks penetrated, and, accordingly, more cracks emerged within the YSZ layers. Even horizontal cracks and partial delaminations were observed. Clearly, the upper part of YSZ coatings became dense (Figure $4 \mathrm{~b}-\mathrm{d}$ ), which implied that the melting and re-solidification of YSZ layers took place as a result of excessive energy input per unit length. As the melting temperature of YSZ is very close to the boiling temperature of the metal feedstock (boiling point of pure nickel is $2730^{\circ} \mathrm{C}$ ), it seems unreasonable that conductive heat transfer from the metal clad, which requires a considerable thermal gradient and thermal conductivity, would cause the observed extent of the heat-affected zone (HAZ).

On the one hand, YSZ in a dense or nanocrystalline morphology is known to have a low coefficient of absorption at the wavelength of the used laser source [22]. This was also observed in the current study for the layer on top of the buried track in Figure $4 \mathrm{~d}$. On the other hand, this cannot be considered equivalent to transparency in general. In studies of the optical properties of plasma-sprayed YSZ in the near infrared (NIR) and long wave infrared (LWIR) range, which are also important for radiative heat transfer in turbine application, it has been shown that, depending on the fraction and morphology of pores, the reflectivity of the TBCs reaches values close to $1[20,23,24]$. Accordingly, laser radiation is not able to dissipate in the depth of the porous substrate but is reflected back to the powder stream. This might result in a multiple forward and backward scattering effect, which effectively causes increased absorption of energy both in the powder and surface near volumes of the porous coating.

\subsection{Sensor Structures Manufactured with Increased Powder Feeding Rates}

Following the hypothesis derived from the first set of experiments, a different approach to limit the heat load to the substrate was chosen in the second set. By increasing the powder feed rate, the fraction of laser intensity reaching the substrate level was reduced due to absorption and reflection from the increased number of feedstock particles $[25,26]$. Additionally, the focus position of the laser beam was changed to achieve a reduced spot size of $156 \mu \mathrm{m}$ in diameter because the minimal bead width was determined by the spot size on the substrate, and clads with reduced dimensions were desired. Finally, the laser power was set to its minimum level of $15 \mathrm{~W}$, and the scanning speed was increased to $1000 \mathrm{~mm} / \mathrm{min}$ to partly compensate for the reduced irradiated surface area.

Photographs of clads deposited with substrate shadowing resulting from high powder feed rates of chromel and alumel, respectively, are shown in Figure 6. Although an avoidance of the formation of a melt pool on the substrate level was desired and the laser power was no longer sufficient to melt the complete amount of feedstock, continuous clads were formed. The latter clearly indicates that the energy absorption was confined to the central overlap of powder, and laser focus and the dissipation of energy as a result of scattering was limited. When the chromel powder feeding rate was higher than $6.9 \mathrm{~g} / \mathrm{min}$, detached tracks could be recognized by shadows observed in Figure 6(1-4). Similarly, detachment of the alumel clads was observed at powder feeding rates higher than $8.9 \mathrm{~g} / \mathrm{min}$ (Figure 6(5-7)). This indicates that the formation of a melt pool at the level of the zirconia surface was completely avoided. To prevent bonding problems, the powder feeding rates of 6.9 and $8.9 \mathrm{~g} / \mathrm{min}$ for chromel and alumel, respectively, were chosen as optimized parameters for the manufacture of thermocouple sensors. 


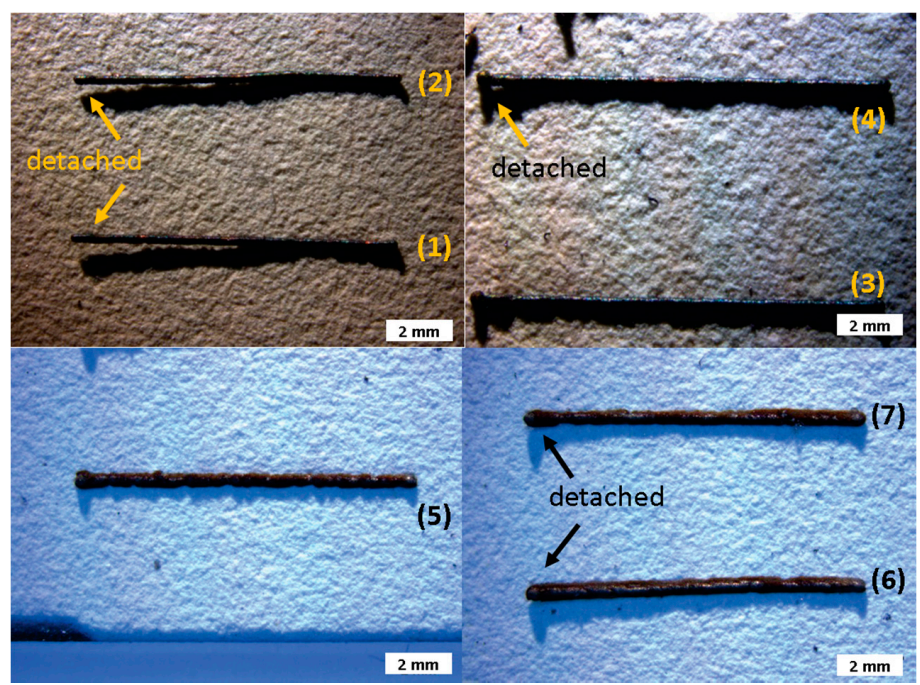

Figure 6. Stereo micrograph of cladded tracks: (1-4) chromel feedstock; (5-7) alumel feedstock. $P_{\mathrm{L}}=15 \mathrm{~W}, v_{\mathrm{S}}=1000 \mathrm{~mm} / \mathrm{min}, d_{\mathrm{S}}=156 \mu \mathrm{m}, f_{\mathrm{C}}=f_{\mathrm{P}}=10 \mathrm{~L} / \mathrm{min}$. (1) $f_{\mathrm{F}}=8.1 \mathrm{~g} / \mathrm{min} ;$ (2) $f_{\mathrm{F}}=7.5 \mathrm{~g} / \mathrm{min}$; (3) $f_{\mathrm{F}}=6.5 \mathrm{~g} / \mathrm{min} ;(4) f_{\mathrm{F}}=6.9 \mathrm{~g} / \mathrm{min} ;(5) f_{\mathrm{F}}=8.9 \mathrm{~g} / \mathrm{min} ;(6) f_{\mathrm{F}}=11.9 \mathrm{~g} / \mathrm{min} ;(7) f_{\mathrm{F}}=10.4 \mathrm{~g} / \mathrm{min}$.

Minimal interference of cladded thermocouple to thermal barrier coatings was desired to keep the original performance of the coatings. Therefore, cross sections of the optimized chromel and alumel tracks were analyzed under a laser microscope and are given in Figure 7. Clearly, no apparent effect occurred at the interface between the YSZ substrate and cladded tracks following the laser cladding process. The resistivity of optimized tracks was examined on the basis of averaged outer dimensions of clads and resistance measured by Four Probe testing. The deduced values of specific resistivity, given in Table 2, are in close agreement with reported bulk resistivity values [21]. Therefore, a close-to-homogeneous track geometry with negligible waists can be stated. This is also supported by the microstructural analysis of clads, showing incidental waists only in case of the alumel thermoleg (Figure 7).

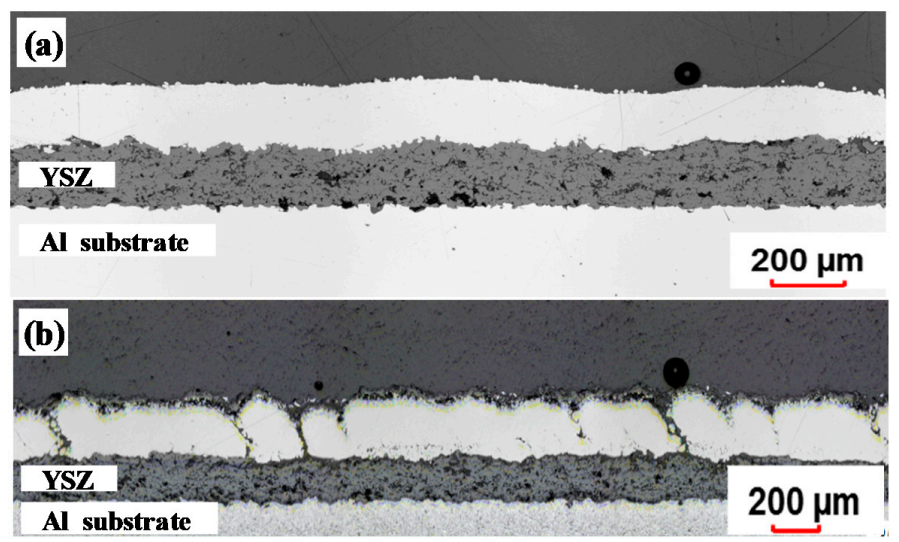

Figure 7. Cross sectional micrographs for optimized tracks: (a) chromel; (b) alumel.

Table 2. Experimental and nominal resistivity of K-type thermocouple.

\begin{tabular}{ccc}
\hline \multirow{2}{*}{ Source } & \multicolumn{2}{c}{ Resistivity $(\mu \Omega \cdot m)$} \\
\cline { 2 - 3 } & Alumel & Chromel \\
\hline Experiment & 0.64 & 0.776 \\
Reported [21] & $0.29-0.33$ & 0.706 \\
\hline
\end{tabular}


Figure 2 shows a photo of an embedded thermocouple and a schematic of the set-up used for collecting temperature signals. The topographies of the cladded thermolegs were analyzed by a Cyberscan topographer before and after embedding with the additional TBC layer. Figure 8 gives a top view of the bare laser-cladded thermocouple (a) as well as the thermocouple which had been covered with a layer of YSZ of $50 \mu \mathrm{m}$ thickness to demonstrate the ability to embed such sensors underneath functional coatings (b). The area scanned with the topographer was restricted to the area where tracks were deposited. The area which had been covered by a second layer of TBC is marked by a blue dashed box. The scales on the right side reveal the height information of the layers. The dimensions were measured giving $184 \pm 5 \mu \mathrm{m}$ in height and $305 \pm 2 \mu \mathrm{m}$ in width for alumel and $211 \pm 3 \mu \mathrm{m}$ in height and $191 \pm 5 \mu \mathrm{m}$ in width for chromel, respectively. The average roughness was also measured to $10 \pm 2 \mu \mathrm{m}$ for alumel and $9 \pm 2 \mu \mathrm{m}$ for chromel, respectively.
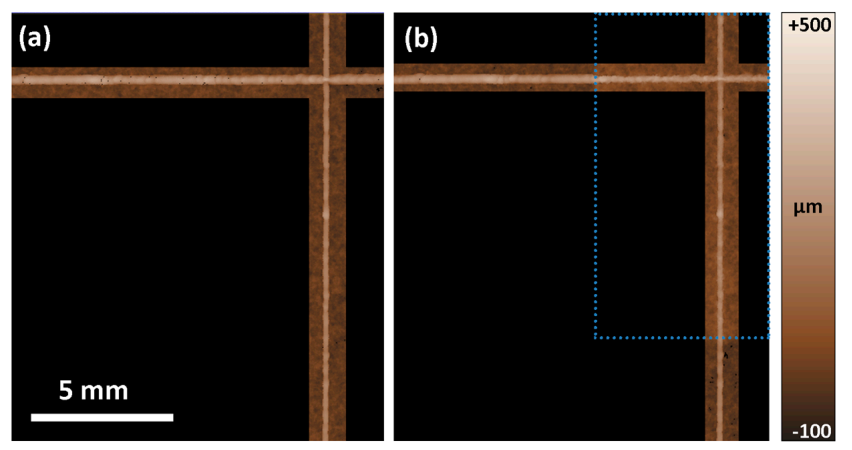

Figure 8. Topography of the cladded K-type thermocouple (a) before and (b) after embedding.

The thermocouple voltage versus temperature data before and after embedding was analyzed as shown in Figure 9. It was determined that the cladded thermocouple had a nearly linear relationship between the thermoelectric output voltage and the temperature within the experimental temperature range (Figure 9a). The Seebeck coefficient of the cladded thermocouple before embedding was estimated as $41.2 \mu \mathrm{V} / \mathrm{K}$, with a regression factor of 0.9999 by a linear fit. Similarly, the Seebeck coefficient of this thermocouple after embedding was about $40.9 \mu \mathrm{V} / \mathrm{K}$ within the measurement error, with a regression factor of 0.99 by a linear fit. There was a delayed response of the embedded thermocouple at the beginning in Figure 9b. This was likely caused by the much lower thermal conductivity of the YSZ layer which caused a delayed temperature increase on the experimental non-steady state conditions. In both cases, the laser-cladded thermocouple yielded a response comparable to the commercial K-type thermocouple and similar to the results reported in Marshall et al. [27]. In conclusion, the fabricated thermocouple possessed high reproducibility during operation before and after embedding.
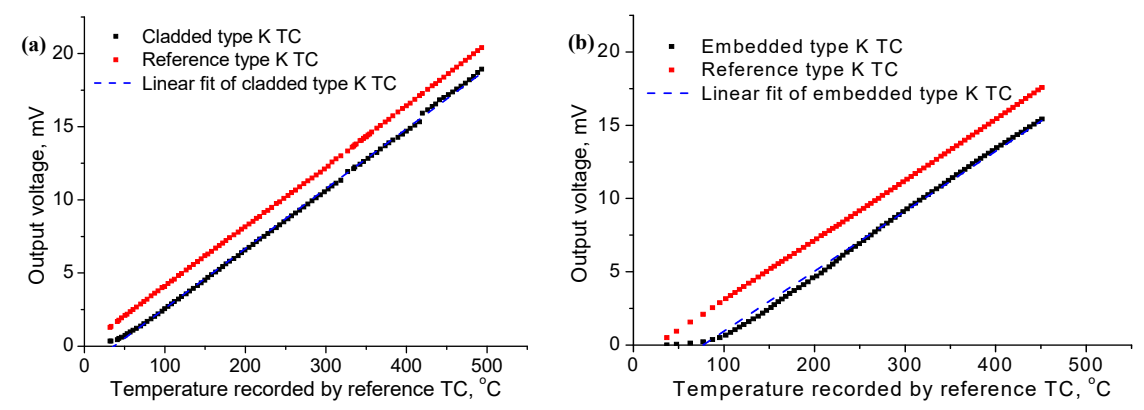

Figure 9. Voltage response of cladded K-type thermocouple from ambient temperature to $450{ }^{\circ} \mathrm{C}$ (a) before and (b) after embedding. 


\section{Summary and Conclusions}

Laser cladding technology has been successfully adopted to produce K-type thermocouple sensors without either vacuum processing or mask application and, simultaneously, with minimal influence to the substrate and small feature sizes $(100-200 \mu \mathrm{m})$. Excellent performance of a cladded K-type thermocouple was confirmed when compared to a commercial K-type thermocouple at temperatures up to $450^{\circ} \mathrm{C}$. Thus, sensors can be directly deposited onto the surface of or even embedded within functional coatings to create a sensor system that can survive in certain thermal environments. The embedded nature of cladded thermocouples also allows temperature measurement at various depths in the TBC material system; this reveals a new field of application for laser cladding technology. Accordingly, laser cladding is a promising process to deposit in situ thermocouples or other sensors, e.g., strain gauges, to realize the real-time temperature or stress monitoring in operation environments.

Author Contributions: This manuscript evolved in major parts from the Ph.D. project of Yanli Zhang, conducted at Forschungszentrum Jülich GmbH [28]. Yanli Zhang, Daniel Emil Mack, Georg Mauer, and Robert Vaßen conceived and designed the experiments; Yanli Zhang performed the experiments; Yanli Zhang and Daniel Emil Mack analyzed the data; Yanli Zhang and Daniel Emil Mack wrote the paper.

Funding: This research was partially funded by the China Scholarship Council (CSC) under grant number [201206020004].

Acknowledgments: The authors also gratefully acknowledge the invaluable support of further colleagues at Forschungszentrum Jülich GmbH (IEK-1): Karl-Heinz Rauwald and Ralf Laufs for the manufacture of the coatings.

Conflicts of Interest: The authors declare no conflict of interest.

\section{References}

1. Padture, N.P.; Gell, M.; Jordan, E.H. Thermal barrier coatings for gas-turbine engine apptications. Science 2002, 296, 280-284. [CrossRef] [PubMed]

2. Khan, A.N.; Lu, J. Behavior of air plasma sprayed thermal barrier coatings, subject to intense thermal cycling. Surf. Coat. Technol. 2003, 166, 37-43. [CrossRef]

3. Vassen, R.; Stuke, A.; Stöver, D. Recent developments in the field of thermal barrier coatings. J. Therm. Spray Technol. 2009, 18, 181-186. [CrossRef]

4. Montemor, M.F. Functional and smart coatings for corrosion protection: A review of recent advances. Surf. Coat. Technol. 2014, 258, 17-37. [CrossRef]

5. Fasching, M.; Prinz, F.B.; Weiss, L. "Smart" coatings: A technical note. J. Therm. Spray Technol. 1995, 4, 133-136. [CrossRef]

6. Lei, J.-F.; Will, H.A. Thin-film thermocouples and strain-gauge technologies for engine applications. Sens. Actuators A Phys. 1998, 65, 187-193. [CrossRef]

7. Senturia, S.D. Microsystems Design; Kluwer Academic Publisher: Norwell, MA, USA, 2001.

8. Theophilou, T.S.; Longtin, J.P.; Sampath, S.; Tankiewicz, S.; Gambino, R.J. Integrated heat-flux sensors for harsh environments using thermal-spray technology. IEEE Sens. J. 2006, 6, 1126-1133. [CrossRef]

9. Longtin, J.P.; Mari, E.; Tan, Y.; Sampath, S. Using thermal spray and laser micromachining to fabricate sensors. J. Therm. Spray Technol. 2011, 20, 958-966. [CrossRef]

10. Longtin, J.; Sampath, S.; Tankiewicz, S.; Gambino, R.J.; Greenlaw, R.J. Sensors for harsh environments by direct-write thermal spray. IEEE Sens. J. 2004, 4, 118-121. [CrossRef]

11. Gutleber, J.; Brogan, J.; Gambino, R.J.; Gouldstone, C.; Greenlaw, R.; Sampath, S.; Longtin, J.; Dongming, Z. Embedded temperature and heat flux sensors for advanced health monitoring of turbine engine components. In Proceedings of the 2006 IEEE Aerospace Conference, Big Sky, MT, USA, 4-11 March 2006; p. 9.

12. Khajepour, A.; Toyserkani, E.; Corbin, S. Laser Cladding; CRC Press: Boca Raton, FL, USA, 2004; ISBN 0849321727.

13. Lin, W.C.; Chen, C. Characteristics of thin surface layers of cobalt-based alloys deposited by laser cladding. Surf. Coat. Technol. 2006, 200, 4557-4563. [CrossRef]

14. Doubenskaia, M.; Smurov, I.; Grigoriev, S.; Pavlov, M. Complex analysis of elaboration of steel-TiC composites by direct metal deposition. J. Laser Appl. 2013, 25, 042009. [CrossRef] 
15. Gao, W.; Zhao, S.; Liu, F.; Wang, Y.; Zhou, C.; Lin, X. Effect of defocus manner on laser cladding of Fe-based alloy powder. Surf. Coat. Technol. 2014, 248, 54-62. [CrossRef]

16. Sun, Y.; Hao, M. Statistical analysis and optimization of process parameters in Ti6Al4V laser cladding using Nd:YAG laser. Opt. Lasers Eng. 2012, 50, 985-995. [CrossRef]

17. Frenk, A.; Kurz, W. Microstructure formation in laser materials processing. Lasers Eng. 1992, 1, $193-212$.

18. Frenk, A.; Vandyoussefi, M.; Wagnière, J.-D.; Kurz, W.; Zryd, A. Analysis of the laser-cladding process for stellite on steel. Metall. Mater. Trans. B 1997, 28, 501-508. [CrossRef]

19. Shinozaki, M.; Clyne, T.W. A methodology, based on sintering-induced stiffening, for prediction of the spallation lifetime of plasma-sprayed coatings. Acta Mater. 2013, 61, 579-588. [CrossRef]

20. Eldridge, J.I.; Spuckler, C.M. Determination of scattering and absorption coefficients for plasma-sprayed yttria-stabilized zirconia thermal barrier coatings. J. Am. Ceram. Soc. 2008, 91, 1603-1611. [CrossRef]

21. Paul, C.P.; Alemohammad, H.; Toyserkani, E.; Khajepour, A.; Corbin, S. Cladding of WC-12Co on low carbon steel using a pulsed Nd:YAG laser. Mater. Sci. Eng. A 2007, 464, 170-176. [CrossRef]

22. Tsukuma, K.; Yamashita, I.; Kusunose, T. Transparent $8 \mathrm{~mol} \% \mathrm{Y}_{2} \mathrm{O}_{3}-\mathrm{ZrO}_{2}$ (8Y) ceramics. J. Am. Ceram. Soc. 2008, 91, 813-818. [CrossRef]

23. Eldridge, J.I.; Spuckler, C.M.; Markham, J.R. Determination of scattering and absorption coefficients for plasma-sprayed yttria-stabilized zirconia thermal barrier coatings at elevated temperatures. J. Am. Ceram. Soc. 2009, 92, 2276-2285. [CrossRef]

24. Stuke, A.; Kassner, H.; Marqués, J.L.; Vassen, R.; Stöver, D.; Carius, R. Suspension and air plasma-sprayed ceramic thermal barrier coatings with high infrared reflectance. Int. J. Appl. Ceram. Technol. 2012, 9, 561-574. [CrossRef]

25. Wen, S.Y.; Shin, Y.C.; Murthy, J.Y.; Sojka, P.E. Modeling of coaxial powder flow for the laser direct deposition process. Int. J. Heat Mass Transf. 2009, 52, 5867-5877. [CrossRef]

26. Ya, W.; Hernández-Sánchez, J.F.; Pathiraj, B.; Veld, A.J.H.I. A study on attenuation of a Nd:YAG laser power by co-axial and off-axial nozzle powder stream during cladding. In Proceedings of the ICALEO 2013-32nd International Congress on Applications of Lasers and Electro-Optics, Miami, FL, USA, 6-10 October 2013; pp. 453-462.

27. Marshall, R.; Atlas, L.; Putner, T. The preparation and performance of thin film thermocouples. J. Sci. Instrum. 1966, 43, 144. [CrossRef]

28. Zhang, Y. Development of Embedded Thermocouple Sensors for Thermal Barrier Coatings (TBCs) by a Laser Cladding Process; Forschungszentrum Jülich GmbH Zentralbibliothek: Jülich, Germany, 2016. 